\title{
Holoprosencephaly and polydactyly: a possible expression of the hydrolethalus syndrome
}

\author{
H Bachman, R D Clark, W Salahi
}

\begin{abstract}
We report two fetuses with hydrocephalus, features of holoprosencephaly, and postaxial polydactyly born to a consanguineous Mexican-American couple. The phenotype is consistent with the hydrolethalus syndrome, although holoprosencephaly has not previously been seen in this condition. We believe other similar cases with a trisomy 13 phenotype but normal chromosomes may also have the hydrolethalus syndrome.
\end{abstract}

In 1981, Salonen et $a l^{1}$ first described a lethal malformation syndrome in 28 Finnish newborns, which they called hydrolethalus. Named for the key features of hydramnios, hydrocephalus, and lethality, hydrolethalus is an autosomal recessive condition also associated with polydactyly, micrognathia, microphthalmia, congenital heart defect, and abnormalities of the respiratory system. In 1987, Anyane-Yeboa et $a l^{2}$ delineated the condition further, noting midline brain abnormalities.

We describe two sibs from a consanguineous union who had many of the features of hydrolethalus and holoprosencephaly.

\section{Case report}

At 15 weeks' gestation, a 29 year old G4,P2,TAB1 Mexican woman with two normal daughters sought medical attention for a fever of $40^{\circ} \mathrm{C}$ owing to pyelonephritis. A routine fetal ultrasound was done which showed an omphalocele, hydrocephalus, hypotelorism, and microphthalmia. An amniocentesis

Division of Medical Genetics, Department of Pediatrics, Harbor-UCLA Medical Center, 1124 W Carson Street, Bldg E-4, Torrance, California 90502, USA.

H Bachman, R D Clark

Department of Pathology, Harbor-UCLA Medical Center, Torrance, California 90502, USA.

W Salahi

Correspondence to $\mathrm{H}$ Bachman.

Received for publication 17 April 1989.

Revised version accepted for publication 7 June 1989. indicated a 46,XY normal male karyotype and normal amniotic $\alpha$ fetoprotein. The pregnancy was electively terminated at 18 weeks' gestation. On examination of the fetus, cebocephaly, bilateral microphthalmia, omphalocele, and postaxial polydactyly of the left hand and foot were noted (fig 1). Trachea and bronchi, lobulation of the lungs, and the heart were normal. There was no dorsal cleft through the occiput, and the shape of the foramen magnum was normal. The frontal bone was missing. The brain showed holoprosencephaly of the lobar type. There was a large common ventricle and the dorsal thalamus and basal ganglia were dysplastic, fused into a midline mass on the posterior inferior ventricular wall. In addition, there was agenesis of the olfactory nerves, optic nerves, oculomotor nerves, corpus callosum, septum pellucidum, hippocampal formation, and the descending tracts, including the corticospinal tract. The cerebellum was severely hypoplastic and there was dysplasia of the midbrain, pons, and inferior olivary nuclei. Microscopic examination of the cerebral cortex showed the usual trilaminar pattern of immaturity, and the cerebellar cortex was normal.

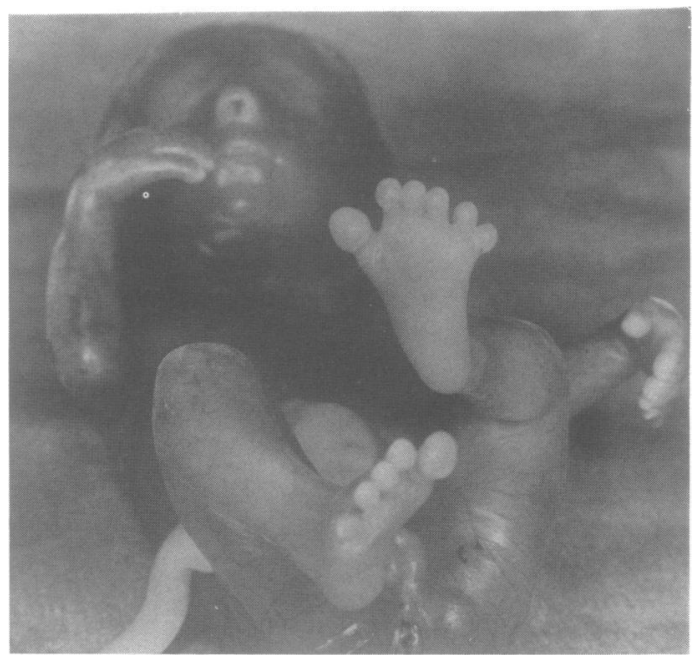

Figure 1 Postmortem view of case 1 showing single nostril, omphalocele, postaxial polydactyly of left hand and foot, and splayed, broad hallux. 


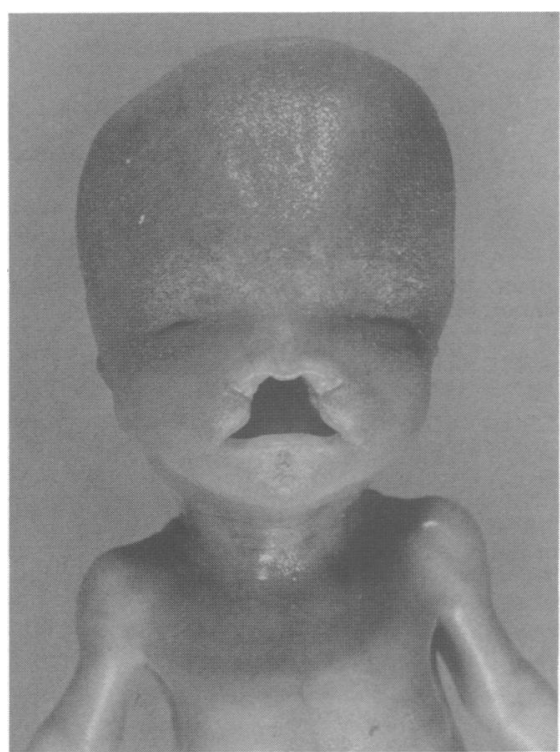

Figure 2 Postmortem view of case 2 showing microphthalmia and premaxillary agenesis causing the midline facial defect.

It was discovered that a previous pregnancy had been electively terminated by prostaglandin induction at 20 weeks after hydrocephalus was seen on ultrasound. A necropsy of this male fetus showed premaxillary agenesis, microphthalmia, hydrocephalus, and postaxial polydactyly of the hands and left foot (fig 2). The brain showed micropolygyria and an incomplete Sylvian fissure bilaterally with total absence of the aqueduct of Sylvius. In addition, cranial nerves I and II, the corpus callosum, and descending tracts including the corticospinal tract were absent. The midbrain, pons, and inferior olivary nuclei were dysplastic. Chromosome studies were not performed.

The family history is remarkable because the parents are third cousins. There are no other affected relatives, although our patient reports that she had a sister who died at a few days of age with a large head. No records are available for this child who was born in Mexico.

\section{Discussion}

We believe that our patients have the hydrolethalus syndrome, as they exhibit almost all of its features: hydrocephalus, midline structural defects of the brain, microphthalmia, omphalocele, and postaxial polydactyly. Our patients did not have defects of the heart or lung. The absence of polyhydramnios may not be valid in our cases because both pregnancies were terminated by 20 weeks' gestation. The most common abnormality in the feet, duplication of the hallux, was lacking; however, our patients did have large, deviated big toes. Finally, the consanguinity in this family supports such an autosomal recessive trait.

Although holoprosencephaly has not specifically been described as a feature of hydrolethalus, in their initial report Salonen et $a l^{1}$ described the absence of midline brain structures in eight of 28 cases. The most detailed description of absent midline brain structures was provided in a case report by Anyane-Yeboa et al. ${ }^{2}$ In that case, gyral patterns were abnormal and olfactory bulbs, tracts, and the anterior commissure were absent. The thalami were fused and mammillary bodies could not be identified. Aughton and Cassidy ${ }^{3}$ described a mild case of hydrolethalus with an absent septum pellucidum and a partial posterior defect in the corpus callosum. Krassikoff et $a l^{4}$ reported a patient with hydrolethalus in whom massive hydrocephalus and holoprosencephaly were noted prenatally by ultrasound. At necropsy, in addition to bilateral postaxial polydactyly of the hands, the most striking feature was a large midline facial defect with absent nasal bone and cartilages and midline cleft lip and palate. The pituitary, corpus callosum, and septum pellucidum were also absent. The lateral ventricles communicated via the subdural space, which resulted in the appearance of holoprosencephaly noted on ultrasound. Thus, although holoprosencephaly in itself is not stressed, absence of midline brain structures is well documented in the hydrolethalus syndrome.

Similar patients, resembling a trisomy 13 phenotype with holoprosencephaly and postaxial polydactyly may also represent hydrolethalus. In 1987, Young and Madders ${ }^{5}$ reported a previously undescribed syndrome of holoprosencephaly, heart defects, and postaxial polydactyly with normal chromosomes. That stillborn male had premaxillary agenesis with bilateral microphthalmia, postaxial polydactyly of the hands, alobar holoprosencephaly with absence of midline structures, pachygyria, and a ventricular and atrial septal defect. The following year Moerman and Fryns ${ }^{6}$ reported a stillborn female with normal chromosomes and similar findings: holoprosencephaly with alobar hydrocephalus, bilateral postaxial polydactyly, neocerebellar hypoplasia, and microphthalmia with retinal dysplasia. The authors considered hydrolethalus in their differential diagnosis, but discounted it in part because of the holoprosencephaly. In addition, Shiota and Tanimura ${ }^{7}$ described a six week male embryo with holoprosencephaly with absence of midline structures, cardiac defects, and bilateral postaxial polydactyly in both arms and legs. Although chromosomes were not analysed, it is possible that this embryo had the same syndrome.

Holoprosencephaly, in which the embryonic forebrain fails to cleave sagittally and transversely, can be 
caused by chromosome abnormalities, teratogens, and many single gene disorders. Cohen ${ }^{8}$ in his largest and most recent review of holoprosencephaly, lists seven autosomal recessive syndromes that have holoprosencephaly as a feature. Hydrolethalus is not specifically mentioned, although the cases of Young and Madders ${ }^{5}$ and Shiota and Tanimura ${ }^{7}$ are listed as 'pseudotrisomy 13 syndrome of unknown genesis'.

We propose that holoprosencephaly is a feature of the hydrolethalus syndrome. Furthermore, the diagnosis of 'pseudotrisomy 13 syndrome' in the case of Young and Madders 5 and other reported cases of holoprosencephaly and postaxial polydactyly should be reconsidered. These cases may also represent hydrolethalus. Finally, hydrolethalus should be considered in the differential diagnosis of any case of holoprosencephaly with other anomalies.
1 Salonen $R$, Herva $R$, Norio $R$. The hydrolethalus syndrome: delineation of a "new", lethal malformation syndrome based on 28 patients. Clin Genet 1981;19:321-30.

2 Anyane-Yeboa K, Collins M, Kupsky W, Maidman J, Malin J, Yeh M. Hydrolethalus (Salonen-Herva-Norio) syndrome: further clinicopathological delineation. Am f Med Genet 1987; 26:899-907.

3 Aughton DJ, Cassidy SB. Hydrolethalus syndrome: report of an apparent mild case, literature review, and differential diagnosis. Am F Med Genet 1987;27:935-42.

4 Krassikoff N, Kolnick L, Gilbert $\mathrm{EF}$. The hydrolethalus syndrome. Birth Defects 1987;23(1):411-9.

5 Young ID, Madders DJ. Unknown syndrome: holoprosencephaly, congenital heart defects, and polydactyly. $\mathcal{F}$ Med Genet 1987;24:714-5.

6 Moerman P, Fryns JP. Holoprosencephaly and postaxial polydactyly: another observation. $\mathcal{F}$ Med Genet 1988;25:501-2.

7 Shiota K, Tanimura T. Holoprosencephaly, ventricular septal defect, and postaxial polydactyly in a human embryo. $\mathcal{F} \mathrm{Med}$ Genet 1988;25:502-3.

8 Cohen $M$. Epidemiology, genetics, and syndromology perspectives on holoprosencephaly. Part 1. Teratology 1989;40:211-35. 